\title{
Different yellowing degrees and the industrial utilization of flue-cured tobacco leaves
}

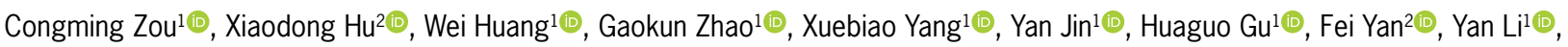 \\ Qun Wu${ }^{1}$, Kaisheng Xiong ${ }^{3 *}(\mathbb{D})$
}

\author{
1Yunnan Academy of Tobacco Agricultural Sciences - \\ 650021 - Kunming -Yunnan - China. \\ ${ }^{2}$ Chuxiong Company of Yunnan Provincial Tobacco \\ Corporation - 675000 - Chuxiong - Yunnan - China. \\ ${ }^{3}$ China Tobacco Yunnan Industrial Co.Ltd -650224 - \\ Kunming - Yunnan - China. \\ *Corresponding author <xxiongks@163.com>
}

Edited by: Paulo Cesar Sentelhas

Received May 03, 2017

Accepted September 17, 2017
ABSTRACT: Yellowing is a key stage in the curing of flue-cured tobacco (Nicotiana tobacum L.) as much of the chemical transformation occurs during this period. This study examined the effect of different yellowing degrees on the value of flue-cured tobacco leaves at the farm level for both processing and manufacturing. The study was conducted in the counties of Chuxiong, Dali, and Yuxi in Yunnan, China over two years. Yellowing treatments have been designed to have either a mild or a regular yellowing degree. Yield, value, appearance, suction property, smoking characteristics, and physical resistance to further processing were investigated to evaluate the effect of degree of yellowing on the industrial utilization of flue-cured tobacco leaves. The regular yellowing degree enhanced yield, value, and appearance compared to the mild yellowing degree, regardless of cultivar or location; however, physical resistance to further processing and the suction property of the mild yellowing degree treatment were better than with the regular yellowing degree regardless of cultivar or location. Furthermore, although the regular yellowing degree recorded higher smoking characteristic scores than the mild yellowing degree immediately after flue-curing, the scores of mild yellowing degree leaves could be further augmented by increasing intensity in the re-drying stage. The smoking characteristic score in the regular yellowing degree can only be increased by low intensity re-drying, and significantly decreased by mild and high intensity re-drying. Therefore, in terms of industrial utilization, mild yellowing is the better choice for flue-curing tobacco. This study also suggested that the current regular yellowing stage in Yunnan should be shortened to meet the demands of the traditional tobacco industry.

Keywords: Hongda cultivar, K326 cultivar, curing barn, re-drying, leaf utility

\section{Introduction}

The flue-curing process is a way of curing fluecured tobacco with artificial heat over a period of 6-7 days (Horne, 1980; Hawks and Collins, 1993; Peele, 2005); it entails a flue-curing stage and a re-drying stage (Figure 1). Multiple factors influence industrial utilization and the style of the tobacco leaf and include the ecological environment, cultivar, maturity, agronomic management, and curing technology (Reed et al., 2012). Among these factors, the yellowing stage in the flue-curing process is a key step during which complex physical, physiological, and biochemical reactions materialize in the tobacco leaves (Bacon et al., 1952; Weston, 1968; Koiwai and Kisaki, 1979; Alejar et al., 1988). Previous studies have focused on various aspects of the curing process for flue-cured tobacco leaves, including temperature, humidity, time, and draft fan control (Zhan et al.,
2011; Cui et al., 2013; Xie et al., 2013). These studies focused mainly on the commercial purchase of tobacco, which is set out as the First Sampling in Figure 1. However, few studies have concentrated on the extent of yellowing and its industrial usability in flue-cured tobacco leaves after threshing and re-drying as represented by the Second Sampling in Figure 1.

The current flue-curing mode for tobacco leaves in Yunnan is standardised to obtain dry, yellow, and fragrant leaves. However, the cigarette manufacturing industry gives poor evaluation scores to such tobacco leaves. A number of indices that are taken seriously in the industry are paid less heed during the flue-curing process. These indices include resistance to further processing, suction properties, shatter resistance, and the smoking characteristics of re-dried tobacco leaves (Walton et al., 1974; Wang et al., 1998). Resistance to further processing, and the suction properties, are closely re-

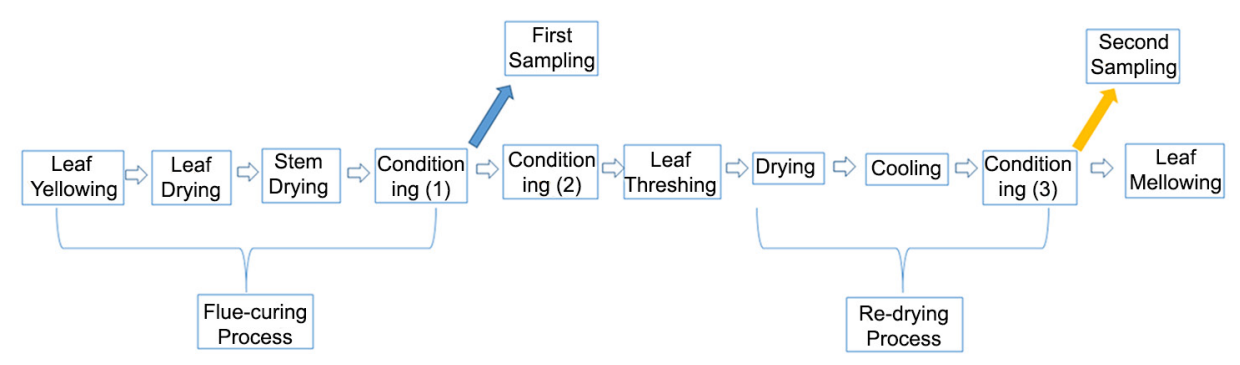

Figure 1 - The process stages for flue-cured tobacco. 
lated to shatter resistance, which refers to the resistance of tobacco leaves to crushing under various mechanical forces. Moreover, shatter resistance has a close correlation with the machining properties of tobacco leaves and exhibits positive correlation with tobacco quality. The absorption equilibrium moisture content (AEMC) and desorption equilibrium moisture content (DEMC) of tobacco leaves exhibit significant correlation with important chemical contents, such as reducing sugar and potassium contents (Wang et al., 2011).

Thus, the aim of this study was to systematically investigate the effect of yellowing degree on the industrial utilization of tobacco leaves during the flue-curing process.

\section{Materials and Methods}

\section{Study site description}

The experiments were performed separately in Chuxiong, Dali, and Yuxi, (the three-major tobaccogrowing regions), Yunnan Province, China, in 2015 and 2016. The curing barns were all bulk curing barns with a horizontal layout. The experiment arrangements are in Table 1 . The three locations are all characterized by mild variation in mean monthly air temperatures, from $10^{\circ} \mathrm{C}$ in Jan to $25^{\circ} \mathrm{C}$ in June, but have a relatively uneven distribution in mean monthly precipitation, with an annual average rainfall of $850 \mathrm{~mm}$ and $80 \%$ of the precipitation occurring from May to Oct in all three locations.

\section{Experiment design}

During the flue-curing process, two treatments were designed: regular yellowing (R) and mild yellowing (M). For regular yellowing, tobacco leaves were wilted at a relatively low temperature (kept in the yellowing stage before $42{ }^{\circ} \mathrm{C}$ ) until they were $80-90 \%$ yellowed. The entire yellowing process included vein yellowing and eventual color fixation after wilting and softening. Regular yellowing is currently the conventional fluecuring mode favored by most tobacco growers. For mild yellowing, tobacco leaves were wilted at a relatively low temperature (yellowing stage) until 60 to $70 \%$ yellowed, and entered the subsequent, higher temperature color fixation/leaf drying stage with yellow lamina but stems still green. The Hongda and K326 cultivars are expressed as $\mathrm{H}$ and $\mathrm{K}$, while Chuxiong, Dali, and Yuxi locations are represented by $\mathrm{C}, \mathrm{D}$, and $\mathrm{Y}$, respectively (Table 2). Flue-curing technology is popular in Yunnan Province given the main change points of temperature and humidity (as measured by a hygrometer) namely, $35 / 33,38 / 35,42 / 36,48 / 37,54 / 38,62 / 39$, and $68 / 39{ }^{\circ} \mathrm{C}$
(Figure 2), respectively. In the treatment process, the turning points were adjusted according to degree of yellowing and the flue-curing time of the tobacco leaves (Table 3). Each treatment had three replications or three curing barns at each location.

Table 3 indicates the time schedule difference between regular yellowing and mild yellowing for both K326 and Hongda cultivars. In the yellowing stage, it took $78 \mathrm{~h}$ for the K326 cultivar to undergo regular yellowing, which was $24 \mathrm{~h}$ longer than with mild yellowing. Similarly, regular yellowing took $23 \mathrm{~h}$ longer than mild yellowing for the Hongda cultivar. In the leaf drying stage, it took $63 \mathrm{~h}$ for the K326 cultivar to undergo mild yellowing, which was $9 \mathrm{~h}$ longer than regular yellowing. Similarly, mild yellowing took 10 more hours than regular yellowing for the Hongda cultivar. There was little difference in the stem drying stage for either treatment. In total, the cumulative curing time was 161 $\mathrm{h}$ regular yellowing in K326, which was 13 more hours than the mild yellowing treatment in K326. The cumulative curing time was $168 \mathrm{~h}$ in the Hongda regular yellowing treatment, which took $12 \mathrm{~h}$ longer than the mild yellowing treatment. Figure 3 presents a comparison of flue-cured K326 leaves (regular v. mild yellowing, Chuxiong County, 2016). The cured leaf chlorophyll data showed that leaf chlorophyll content (leaf chlorophyll $\mathrm{a}+\mathrm{b})$ was $8.5 \mathrm{\mu g} \mathrm{g}^{-1}$ for mild yellowing, while regular yellowing resulted in a chlorophyll content of $7.2 \mu \mathrm{g} \mathrm{g}^{-1}$.

In order to make a judgement about which fluecuring treatment (mild or regular) left more space or potential for improving the smoking characteristics in re-drying or further physical processing, the re-drying intensity levels, including low-, mild-, and high-intensity re-drying processes, were examined for the re-drying trial.

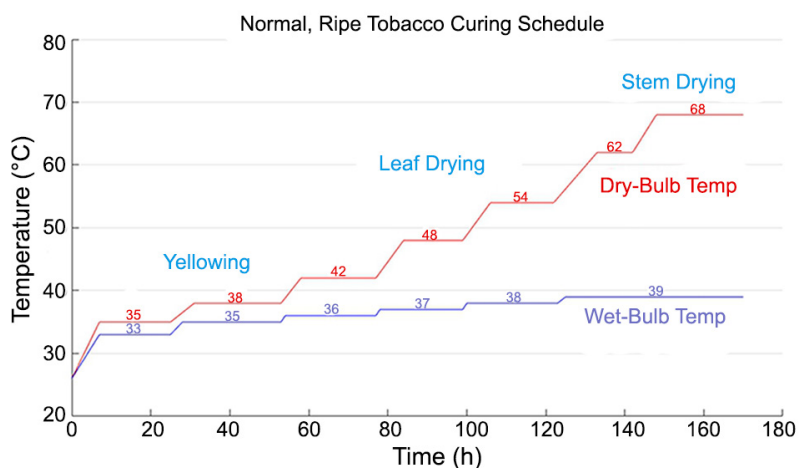

Figure 2 - The typical flue-curing scheme for Yunnan flue-cured tobacco.

Table 1 - Experiment arrangements.

\begin{tabular}{|c|c|c|c|c|}
\hline Time & Site & Cultivar & Area & Leaf Position \\
\hline 2015 & Miaojie village, Weishan county, Dali (24¹9'1.39" N 102³8'17.28” E; Latitude 1720 m) & Hongda & 8 ha & Middle \\
\hline 2015 & Majiazhuang village, Jiangchuan county, Yuxi (25²6’56.04" N 101³3'7.26" E; Latitude 1940 m) & K326 & 8 ha & Middle \\
\hline 2016 & Panmao village, Muding county, Chuxiong (25¹8'26.56" N 100¹6'78.53" E; Latitude 1762 m) & K326 & 13 ha & Middle \\
\hline
\end{tabular}


Table 2 - Experiment codes.

\begin{tabular}{lcccc}
\hline Treatment Code & Year & Site & Cultivar & Treatment \\
\hline DHM & 2015 & Dali & Hongda & Mild \\
DHR & 2015 & Dali & Hongda & Regular \\
YKM & 2015 & Yuxi & K326 & Mild \\
YKR & 2015 & Yuxi & K326 & Regular \\
CKM & 2016 & Chuxiong & K326 & Mild \\
CKR & 2016 & Chuxiong & K326 & Regular \\
\hline
\end{tabular}

Note: For treatment code, Chuxiong, Dali, and Yuxi, locations are represented by $\mathrm{C}, \mathrm{D}$, and $\mathrm{Y}$, respectively. The Hongda and $\mathrm{K} 326$ cultivars are expressed as $\mathrm{H}$ and $\mathrm{K}$, respectively. $\mathrm{M}$ and $\mathrm{R}$ refer to mild or regular yellowing degree, respectively.

Table 3 - Flue-curing time required from regular yellowing to mild yellowing (unit: hours).

\begin{tabular}{lcccc}
\hline Treatment Code & Yellowing & Leaf drying & Stem drying & Total \\
\hline KM & 54 & 63 & 31 & 148 \\
KR & 78 & 54 & 29 & 161 \\
HM & 56 & 68 & 32 & 156 \\
HR & 79 & 58 & 31 & 168
\end{tabular}

Note: KM refers to K326 with mild yellowing treatment; KR refers to K326 with regular yellowing treatment; HM refers to Hongda with mild yellowing treatment; HR refers to Hongda with regular yellowing treatment.

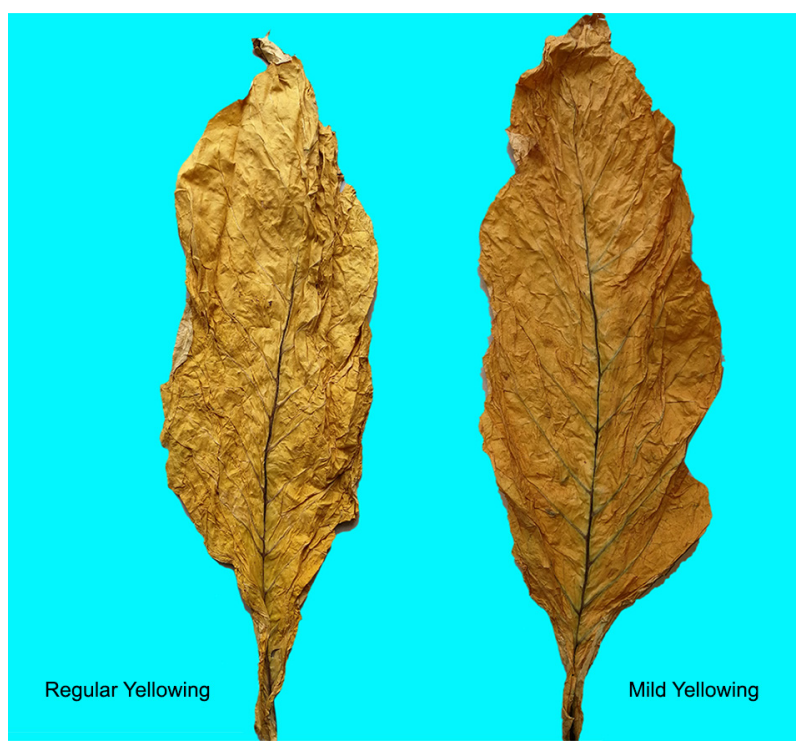

Figure 3 - Regular yellowing vs. mild yellowing treatments for fluecured leaves (K326 cultivar).

\section{Field agronomic management}

The Hongda, and K326, cultivars were produced using high-quality and high-efficiency cultivation techniques with balanced nutrition, normal growth, and fresh leaves yellowed and matured on a layer-by-layer basis. In Aug, after cultivating for 90 to 95 days and topping for 35 to 40 days, the tobacco leaves turned pale yellow and $80 \%$ of them were yellowed, with white and bright main veins, white branch veins, and down-rolled leaf apices and leaf margins. When the leaves were wrinkled, the $12^{\text {th }}$ to the $14^{\text {th }}$ mature leaves were collected and flue-cured according to experiment requirements. Other agronomic practices were conducted according to local standards for cultivating high-quality tobacco.

\section{Parameters}

\section{Yield and quality of tobacco leaves}

All of the samples were preserved after flue-curing to describe their appearance. According to GB2635-92, which is the standard flue-cured tobacco grading system in China, the flue-cured tobacco leaves were graded, and the proportions of lower-, middle-, and higher-grade tobacco leaves, and those of orange and greenish tobacco leaves, were calculated along with their average prices.

\section{Industrial appearance quality}

$\mathrm{C} 2 \mathrm{~F}$ and $\mathrm{C} 3 \mathrm{~F}$ were the typical grades of flue-cured tobacco for conducting research and testing. After removing greenish tobacco from the flue-cured tobacco leaves, $10 \mathrm{~kg}$ of $\mathrm{C} 2 \mathrm{~F}$ and $\mathrm{C} 3 \mathrm{~F}$ samples were separately evaluated based on the Tobacco Industrial Classification Standard.

\section{Physical resistance to further processing}

$\mathrm{C} 2 \mathrm{~F}$ and $\mathrm{C} 3 \mathrm{~F}$ samples, each of $10 \mathrm{~kg}$ in mass, were also separately taken to conduct conventional chemical composition analysis after removing greenish tobacco from the flue-cured tobacco leaves. After equilibration for $72 \mathrm{~h}$ at constant temperature $\left(22^{\circ} \mathrm{C}\right)$ and humidity (60 \%) levels, the samples were analysed according to the method for detecting the shatter resistance index of tobacco leaves provided by Chen et al. (2011).

\section{Absorption and desorption properties}

The absorption and desorption properties of the samples were assayed by the SPSx moisture-retention instrument for tobacco leaves. The detection conditions were as follows: the original environment temperature and relative humidity $(\mathrm{RH})$ were $25{ }^{\circ} \mathrm{C}$ and $60 \%$, respectively. Next, they were adjusted to $25{ }^{\circ} \mathrm{C}$ and $75 \%$, respectively, after reaching equilibrium before studying the absorption and desorption properties of the samples. Subsequently, after reaching equilibrium, the ambient temperature and $\mathrm{RH}$ were adjusted to $25^{\circ} \mathrm{C}$ and $60 \%$ once again to observe the absorption and desorption that had taken place.

\section{Smoking characteristics}

$\mathrm{C} 2 \mathrm{~F}$ and $\mathrm{C} 3 \mathrm{~F}$ samples, each of $5 \mathrm{~kg}$ mass, were separately taken to evaluate the smoking characteristics and quality after removing greenish tobacco from the flue-cured tobacco leaves. After re-drying, the scored smoking characteristics were provided by testers employed by the re-drying enterprise. Each sample was evaluated by seven certified experts and the results were the mean of seven reports. 


\section{Statistical analyses}

Data were analysed by the General Linear Model (GLM) Procedure in SAS (Statistical Analysis System, version 9.3). Replicate measurements on composite leaf samples were averaged for statistical analysis of the treatment effects. Treatment effects were declared significant when the probability $(p)$ of a greater $\mathrm{F}$ statistic was $\leq 0.05$. Mean separation was undertaken by Tukey's honest significant difference (HSD) test at the $95 \%$ level of confidence. For smoking characteristics, the data shown in this study was the average of seven reports.

\section{Results}

\section{Effect on yield and quality of tobacco leaves}

During the production of tobacco leaves, yield and quality are mainly influenced by factors such as climate, soil, cultivation, harvest maturity, and degree of yellowing in the flue-curing process. The position, shape, physical feeling and color are the four key components of leaves which determine tobacco value in China. In this study, tobacco leaves with the same position and shape were cured and evaluated to identify the degree of yellowing that would exert a significant influence on the final yield and quality. The highest quality tobacco leaves were obtained after regular yellowing in the flue-curing process, which is conducive to increasing the flue-curing quality. High-class tobacco leaves, thus processed, exhibited maximum proportions of 78$84 \%$ after different degrees of yellowing, respectively (Table 4). Moreover, mid- to high-class tobacco leaves, processed using regular yellowing, exhibited maximum proportions of 96-98\%, respectively, while fetching average prices of 30.50 to 34.77 yuan.

\section{Effect on appearances of tobacco leaves}

The appearance of the submitted samples was assessed against the Tobacco Industrial Classification Standard and the classifications of different samples are summarised in Table 5. CO2 indicates the highestclass level of tobacco leaves in the middle stalk position, while minor components indicate the acceptable level of tobacco leaves. The samples in the three experi-

Table 4 - Effect of yellowing degree on tobacco leaf yield.

\begin{tabular}{lccc}
\hline Treatment & High-class leaves & High-mid class leaves & Average price \\
\cline { 2 - 3 } & & $\%$ & yuan $\mathrm{kg}^{-1}$ \\
DHM & $53 \mathrm{~b}$ & $95 \mathrm{a}$ & $25.34 \mathrm{~b}$ \\
DHR & $79 \mathrm{a}$ & $96 \mathrm{a}$ & $31.28 \mathrm{a}$ \\
YKM & $58 \mathrm{~b}$ & $97 \mathrm{a}$ & $24.90 \mathrm{~b}$ \\
YKR & $84 \mathrm{a}$ & $98 \mathrm{a}$ & $30.50 \mathrm{a}$ \\
CKM & $65 \mathrm{~b}$ & $95 \mathrm{a}$ & $32.75 \mathrm{~b}$ \\
CKR & $78 \mathrm{a}$ & $97 \mathrm{a}$ & $34.77 \mathrm{a}$ \\
\hline
\end{tabular}

Note: Standardised by selling price of tobacco leaves in that year; different letters indicate a statistically significant difference at $p \leq 0.05$. For treatment, Chuxiong, Dali, and Yuxi, locations are represented by C, D, and Y, respectively. The Hongda and $\mathrm{K} 326$ cultivars are expressed as $\mathrm{H}$ and $\mathrm{K}$, respectively. $\mathrm{M}$ and $\mathrm{R}$ refer to mild or regular yellowing degree, respectively. ment sites subjected to regular yellowing exhibited the best appearance with the highest proportion of $\mathrm{CO} 2$ and lowest proportion of minor components. This was most significantly reflected in tobacco leaves from Chuxiong where there was a difference in proportion $(24 \%)$ of $\mathrm{CO} 2$ in tobacco leaves in the two treatments.

\section{Effect on physical resistance to further processing}

The samples were analysed after pre-treatment according to the method for detecting the shatter resistance index provided by Chen et al. (2011). The proportions of tobacco leaves $<1 \mathrm{~mm}$ and $\geq 4 \mathrm{~mm}$ from the samples in the three experiment sites subjected to mild yellowing exhibited the best shatter resistance (Table 6). Of the three experiment sites the tobacco leaves in Chuxiong showed the best physical resistance to further processing. The shatter resistance of flue-cured tobacco leaves decreased as the degree of yellowing increased.

\section{Effect on the absorption and desorption properties}

During processing, tobacco leaves with a large moisture absorption rate readily absorb moisture during storage and transportation, thus increasing the shatter resistance and decreasing the losses due to shattering. In contrast, tobacco leaves with a large moisture desorption rate readily lose moisture in the re-drying process to achieve ideal moisture conditions. Thus, the shatter resistance decreases while the losses due to shattering increase. For moisture absorption and desorption characteristics, fewer hours indicate a higher absorption rate. The moisture absorption and desorption rates of flue-cured tobacco leaves both decreased with increased degree of yellowing in the flue-curing process.

The samples of the three experiment sites subjected to mild yellowing exhibited the largest moisture absorption and desorption rates (Table 7). Moreover, the moisture absorption and desorption rates of the Hongda cultivar were both less than those of the K326 cultivar at each location. In terms of sites, the moisture absorption rate of the tobacco leaves in Chuxiong was greater than those in Dali and Yuxi, while the moisture desorption rate of the first was lower than those of the last.

Table 5 - Effect of yellowing degree on tobacco leaf appearance.

\begin{tabular}{|c|c|c|c|c|c|}
\hline Treatment & $\begin{array}{l}\text { Gross } \\
\text { mass }\end{array}$ & $\begin{array}{l}\mathrm{CO} 2 \\
\text { mass }\end{array}$ & $\begin{array}{c}\text { CO2 } \\
\text { content }\end{array}$ & $\begin{array}{l}\text { Mass of minor } \\
\text { components }\end{array}$ & $\begin{array}{l}\text { Proportion of minor } \\
\text { components }\end{array}$ \\
\hline & $-\mathrm{k}$ & - & $\%$ & $\mathrm{~kg}$ & $\%$ \\
\hline HM & $28.40 \mathrm{a}$ & $20.10 b$ & $71 \mathrm{~b}$ & $8.20 \mathrm{a}$ & $29 a$ \\
\hline DHR & $31.20 \mathrm{a}$ & $25.40 \mathrm{a}$ & $81 \mathrm{a}$ & $5.60 \mathrm{~b}$ & $18 \mathrm{~b}$ \\
\hline YKM & $31.65 \mathrm{a}$ & $23.40 \mathrm{~b}$ & $74 \mathrm{~b}$ & $8.10 a$ & $26 \mathrm{a}$ \\
\hline YKR & $29.75 \mathrm{a}$ & $25.10 \mathrm{a}$ & $84 \mathrm{a}$ & $4.45 b$ & $15 \mathrm{~b}$ \\
\hline CKM & $30.40 \mathrm{a}$ & $18.70 \mathrm{~b}$ & 62 b & $11.55 \mathrm{a}$ & $38 a$ \\
\hline CKR & $29.15 \mathrm{a}$ & $25.15 a$ & $86 \mathrm{a}$ & $2.95 b$ & $10 \mathrm{~b}$ \\
\hline
\end{tabular}

Note: the higher $\mathrm{CO} 2$ proportion indicates a higher-grade classification; different letters indicate a statistically significant difference at $p \leq 0.05$. For treatment, Chuxiong, Dali, and Yuxi, locations are represented by $\mathrm{C}, \mathrm{D}$, and $\mathrm{Y}$, respectively. The Hongda and $\mathrm{K} 326$ cultivars are expressed as $\mathrm{H}$ and $\mathrm{K}$, respectively. M and R refer to mild or regular yellowing degree, respectively. 


\section{Effect on smoking characteristics}

The smoking characteristics of the tobacco leaves subjected to regular yellowing obtained at the three experiment sites (Figure 1, First Sampling) were superior to those using mild yellowing (Table 8), and were reflected, in the main, by indices including aroma, aroma quantity, aroma quality, and purity. In terms of test sites, the smoking characteristics of tobacco leaves from Dali and Yuxi were superior to those from Chuxiong, which was primarily reflected in three indices including irritability, offensive odor, and purity; however, the aftertaste of tobacco leaves from Chuxiong was better than those from the other two experiment sites. Various technologies such as re-drying are required in industrial processes based on industrial demands. However, according to feed-back related to industrial products, although tobacco leaves subjected to regular yellowing had a high score, they offered a thin smoke, light offensive odors, and a poor after-taste. Thus, the tobacco quality, close to that subjected to a re-drying process, cannot be as readily adjusted on the scale of industrial production. In contrast, tobacco leaves subjected to mild yellowing offered thick smoke and an intense impact, but were irritating; thus, their quality can be improved further according to industrial needs after the re-drying process.

\section{Effect on smoking characteristics of re-dried tobacco leaves}

The score representing the smoking characteristics of tobacco leaves subjected to mild yellowing increased (i.e., improved) with increasing intensity in the re-drying stage (Table 9). However, the score when using regular yellowing can rise when subjected to mild re-drying while the total smoking characteristic score

Table 6 - Effect of yellowing degree on physical resistance to further processing.

\begin{tabular}{|c|c|c|c|c|}
\hline Treatment & Proportion $\geq 4 \mathrm{~mm}$ & Proportion $\geq 2 \mathrm{~mm}$ & Proportion $\geq 1 \mathrm{~mm}$ & Proportion < $1 \mathrm{~mm}$ \\
\hline & & & & \\
\hline DHM & 94.0 a & $1.5 \mathrm{~b}$ & 0.9 a & $3.0 \mathrm{~b}$ \\
\hline DHR & $93.5 b$ & $1.8 \mathrm{a}$ & $0.8 \mathrm{a}$ & $3.6 \mathrm{a}$ \\
\hline YKM & $94.1 \mathrm{a}$ & $1.6 \mathrm{~b}$ & $1.0 \mathrm{a}$ & $2.8 \mathrm{a}$ \\
\hline YKR & $93.7 \mathrm{~b}$ & $1.7 \mathrm{a}$ & $1.0 \mathrm{a}$ & $2.9 \mathrm{a}$ \\
\hline CKM & $96.2 \mathrm{a}$ & $1.3 b$ & $0.9 a$ & $0.4 \mathrm{~b}$ \\
\hline
\end{tabular}

Evaluation standard: the larger the proportion $<1 \mathrm{~mm}$, the worse the shatter resistance of the samples, while the larger the proportion $\geq 4 \mathrm{~mm}$, the better the shatter resistance thereof; different letters indicate a statistically significant difference at $p \leq 0.05$. For treatment, Chuxiong, Dali, and Yuxi, locations are represented by $\mathrm{C}, \mathrm{D}$, and $\mathrm{Y}$, respectively. The Hongda and $\mathrm{K} 326$ cultivars are expressed as $\mathrm{H}$ and $\mathrm{K}$, respectively; $\mathrm{M}$ and $\mathrm{R}$ refer to mild or regular yellowing degrees, respectively.

Table 7 - Effect of yellowing degree on moisture absorption and desorption properties.

\begin{tabular}{lcccc}
\hline Treatment & $\begin{array}{c}\text { Equilibration time at } \\
60 \%-75 \% \mathrm{RH}\end{array}$ & $\begin{array}{c}\text { Equilibrium mass changes at } \\
60-75 \% \mathrm{RH}\end{array}$ & $\begin{array}{c}\text { Equilibration time at } \\
75 \%-60 \% \mathrm{RH}\end{array}$ & $\begin{array}{c}\text { Equilibrium mass changes at } \\
75 \%-60 \% \mathrm{RH}\end{array}$ \\
\hline & $\mathrm{h}$ & $\%$ & $\mathrm{~h}$ & $\%$ \\
DHM & $10.8 \mathrm{~b}$ & $17.3 \mathrm{a}$ & $16.5 \mathrm{~b}$ & $15.3 \mathrm{a}$ \\
DHR & $15.5 \mathrm{a}$ & $15.4 \mathrm{a}$ & $29.3 \mathrm{a}$ & $11.9 \mathrm{~b}$ \\
YKM & $8.0 \mathrm{~b}$ & $16.9 \mathrm{a}$ & $20.6 \mathrm{~b}$ & $13.4 \mathrm{a}$ \\
YKR & $10.5 \mathrm{a}$ & $20.2 \mathrm{a}$ & $25.4 \mathrm{a}$ & $12.0 \mathrm{~b}$ \\
CKM & $6.8 \mathrm{~b}$ & $20.2 \mathrm{a}$ & $16.4 \mathrm{~b}$ & $8.2 \mathrm{a}$ \\
CKR & $8.8 \mathrm{a}$ & $22.9 \mathrm{a}$ & $18.6 \mathrm{a}$ & $4.6 \mathrm{~b}$ \\
\hline
\end{tabular}

Note: equilibration time at $60 \%-75 \% \mathrm{RH}$ indicates absorption, and that at $75 \%-60 \% \mathrm{RH}$ indicates desorption; a lower number of hours indicates a higher absorption or desorption rate; different letters indicate a statistically significant difference at $p \leq 0.05$. For treatment, Chuxiong, Dali, and Yuxi, locations are represented by $\mathrm{C}, \mathrm{D}$, and $\mathrm{Y}$, respectively. The Hongda and $\mathrm{K} 326$ cultivars are expressed as $\mathrm{H}$ and $\mathrm{K}$, respectively. $\mathrm{M}$ and $\mathrm{R}$ refer to mild or regular yellowing degree, respectively.

Table 8 - Effect of different yellowing degree on smoking characteristics.

\begin{tabular}{|c|c|c|c|c|c|c|c|c|c|c|c|}
\hline Treatment & $\begin{array}{c}\text { Aroma } \\
(10)\end{array}$ & $\begin{array}{c}\text { Aroma quantity } \\
\text { (15) }\end{array}$ & $\begin{array}{c}\text { Aroma quality } \\
\text { (15) }\end{array}$ & $\begin{array}{c}\text { Concentration } \\
\text { (10) }\end{array}$ & $\begin{array}{l}\text { Irritability } \\
\text { (15) }\end{array}$ & $\begin{array}{c}\text { Impact } \\
\text { (5) }\end{array}$ & $\begin{array}{l}\text { Offensive odors } \\
\text { (10) }\end{array}$ & $\begin{array}{l}\text { Purity } \\
\text { (10) }\end{array}$ & $\begin{array}{l}\text { Wetness } \\
\text { (5) }\end{array}$ & $\begin{array}{l}\text { After-taste } \\
\text { (5) }\end{array}$ & Sum \\
\hline$\overline{\mathrm{DHM}}$ & 7.5 & 12.5 & 12.5 & 7.5 & 13.0 & 5.0 & 7.5 & 7.5 & 4.0 & 3.5 & 80.5 \\
\hline DHR & 8.5 & 13.0 & 13.0 & 8.5 & 13.0 & 5.0 & 8.5 & 8.5 & 4.0 & 3.5 & 85.5 \\
\hline YKM & 7.5 & 12.5 & 12.5 & 7.5 & 13.0 & 5.0 & 7.5 & 7.5 & 4.0 & 3.5 & 80.5 \\
\hline YKR & 8.0 & 13.0 & 13.0 & 8.0 & 13.0 & 5.0 & 8.0 & 8.0 & 4.0 & 3.5 & 83.5 \\
\hline CKM & 7.5 & 12.5 & 12.4 & 7.3 & 7.5 & 4.9 & 7.1 & 7.3 & 4.0 & 3.9 & 74.4 \\
\hline CKR & 8.0 & 13.0 & 13.5 & 7.5 & 7.5 & 5.0 & 7.5 & 7.5 & 4.0 & 4.0 & 77.5 \\
\hline
\end{tabular}

Note: each leaf sample was evaluated by seven certified experts and the data in this table are the mean of seven reports. For treatment, Chuxiong, Dali, and Yuxi, locations are represented by C, D, and Y, respectively. The Hongda and K326 cultivars are expressed as H and K, respectively. M and R refer to mild or regular yellowing degree, respectively. 


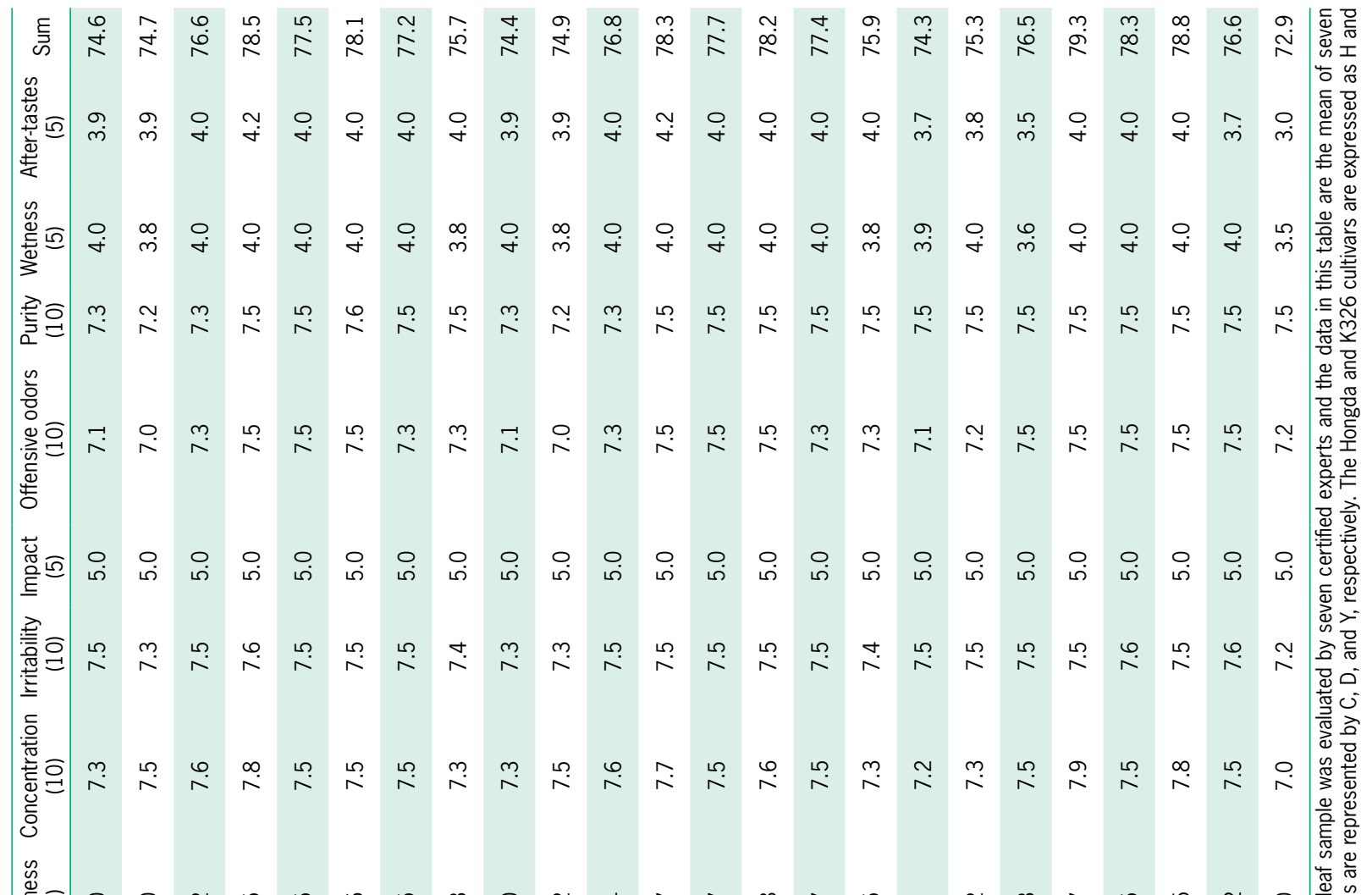

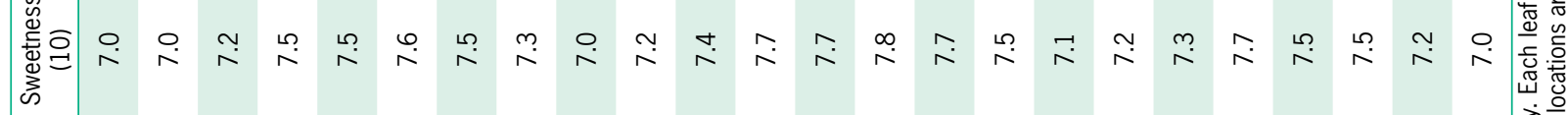

帝

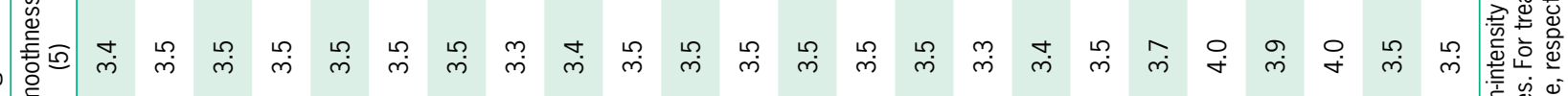

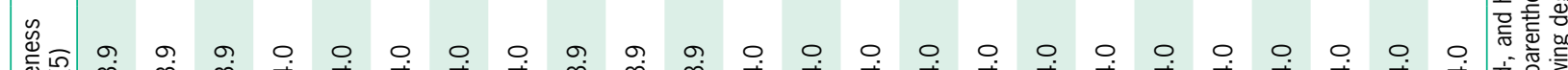

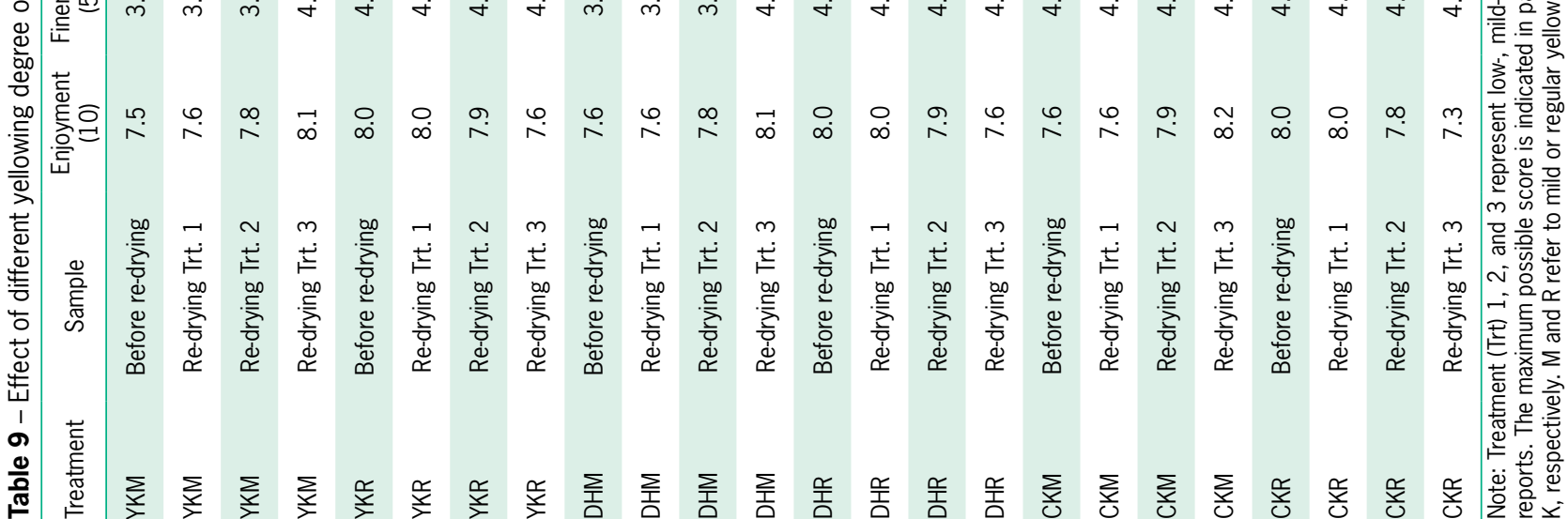


decreased with a mid-and/or high-intensity re-drying process. Moreover, tobacco leaves subjected to mild yellowing with three re-drying stages, and those using regular yellowing with one re-drying stage, exhibited the best smoking characteristics. The trend was similar in each location regardless of cultivar. Thus, mild yellowing can most favorably meet the demands of industry according to the requirements of the industrial re-drying processes used.

\section{Discussion}

\section{Effect on yield and value of tobacco leaves}

In flue-cured tobacco production, the flue-curing process exerts an important influence on the yield and value of tobacco leaves and directly influences the appearance of flue-cured tobacco leaves and conversion of internal chemical constituents, such as polyphenols (Roberts, 1941; Gong et al., 2009). Specifically, the degree of yellowing plays an important role in the whole curing process because the peak period of the conversion of primary chemical components in fresh tobacco leaves occurs upon yellowing, which is extremely important when forming tobacco quality (Gong et al., 1996). Different degrees of yellowing can directly influence the appearance of flue-cured tobacco leaves, their chemical composition, the coordination and contents of neutral aroma components, and production value (Qian et al., 2012; Liu et al., 2015). The appearance of the Hongda cultivar improved with increased yellowing, while in terms of chemical composition, the total nitrogen content gradually decreased, the reducing sugar content increased, and there was no significant influence on other indices (Wang et al., 2007; He et al., 2014). These results are similar to those obtained by Qian et al. (2012).

The authors of much other research believe fluecured tobacco leaves have the greatest yield with a regular degree of yellowing while Qian et al. (2012) suggest that different degrees of yellowing can influence the yield and value of flue-cured tobacco. Most previous research is based on the processes used in tobacco leaf production and has concentrated on yellowing standards in different ecological environments, for other cultivars, locations, and curing barns. Similarly, it is generally believed that 80 to $90 \%$ is considered as optimal yellowing for middle tobacco leaves (Song et al., 2010); however, the re-drying process was given greater attention in the Song et al. (2010) study. The purpose of re-drying tobacco leaves is to achieve and control a uniform moisture content within a certain range so that physico-chemical properties of tobacco leaves change favorably and consistently. This can improve the quality of tobacco leaves and makes their storage easier, thus benefiting industrial production. Compared with flue-curing, re-drying provides better control and has a greater effect on various aspects of tobacco leaves including physical, physiological, biochemical, quality, safety, individuation, and specialization. In our study, regular yellowing treatment (R) resulted in a higher proportion of high quality leaves as determined by the current market grading system, and higher average prices, compared to mild yellowing treatment (M). Therefore, from the grower's perspective, regular yellowing is the proper choice. This will be true until prices of grades are adjusted to reflect the greater value of tobacco from mild yellowing at the manufacturing stage.

\section{Effect on industrial appearance, resistance to further processing, and absorption and desorption properties}

The industrial appearance of flue-cured tobacco leaves was consistent with grade quality evaluation of appearance in commercial systems, and that obtained using regular yellowing was slightly higher than that resulting from mild yellowing. However, in view of the industrial processes used in flue-cured tobacco, mild yellowing was superior to regular yellowing. The moisture absorption characteristics and resistance to further processing of flue-cured tobacco leaves directly influenced the crumbliness of the leaves during processing. Generally speaking, more than $5 \%$ of tobacco material is lost from tobacco leaves with poor resistance to further processing during subsequent defoliation and cigarette manufacture: this causes losses and increases the cost of tobacco and directly influences the economic value of tobacco leaves (Mutasa et al., 1990). Thus, the physical resistance to further processing of tobacco leaves is the focus of enterprises involved in re-drying tobacco and the greater the physical resistance to further processing, the less the loss of tobacco during defoliation. The data show that physical resistance to further processing represented by shatter resistance decreases as yellowing increases. Therefore, tobacco leaves with mild yellowing are easily processed during defoliation. With a rapid moisture absorption rate, tobacco leaves can quickly absorb moisture to enable defoliation in the re-drying process. Similarly, with a rapid moisture desorption rate, moisture in tobacco leaves can be quickly lost in the attempt to reach the required dry state. The data show that the moisture absorption and desorption rates of tobacco leaves with mild yellowing are greater than those of tobacco leaves with regular yellowing. Therefore, tobacco leaves with mild yellowing are more easily processed (i.e., defoliated and re-dried). From the perspective of appearance, it is appropriate to choose a slightly higher degree of yellowing, while mild yellowing is more conducive to physical resistance to further processing and improved suction properties.

\section{Effect on smoking characteristics of flue-cured, and re-dried tobacco leaves}

Smoking characteristic scores are a core index used to evaluate the quality of tobacco leaves and the primary method of assessing the internal quality of tobacco leaves (Stedman, 1968; White et al., 1979; Weybrew et al., 1983; Tso, 1990); however, evaluating the 
influence of the flue-curing process on tobacco qualities generally focuses on the smoking characteristics of tobacco leaves after flue-curing (Dai et al., 2008). The curing processes include flue-curing and re-drying; thus, , the quality of tobacco leaves evaluated on the basis of the smoking characteristics of re-dried tobacco leaves is closer to that of 'as-produced' cigarettes and exhibits broader significance. This research studied the influence of different degrees of yellowing in flue-curing process on the smoking characteristics of re-dried tobacco to further optimize flue-curing processes. After being treated with different intensities in the re-drying stages, tobacco leaves with different degrees of yellowing had dissimilar smoking characteristics. In view of the processing effect, tobacco leaves with mild yellowing were more conducive to subsequent re-drying efficacy compared with the current degree of yellowing seen in flue-curing processes.

\section{Conclusions}

The following conclusions are drawn from the experiments undertaken at three sites over a two-year period: first, in view of grower income, the appearance, proportion of upper-class tobacco leaves, and proportions and average prices of middle- and upper-class tobacco leaves subjected to regular yellowing are superior to those subjected to mild yellowing, regardless of cultivar. Second, from the perspective of industrial flue-cured tobaccos, samples with mild yellowing exhibit the greatest shatter resistance among the tobacco leaves tested and there is no significant difference between cultivars. Moreover, among the samples collected from the three sites, the samples with mild yellowing show quicker moisture absorption and desorption rates than those subjected to regular yellowing. Third, the scored smoking characteristics of tobaccos subjected to the flue-curing process with a regular degree of yellowing at the three test sites were all higher than those with mild yellowing. Despite this, the quality of fluecured tobaccos with regular yellowing could be adjusted slightly from an industrial point of view and smoking scores decreased as intensity during the re-drying stage increased. In comparison, the quality of tobacco leaves with mild yellowing could be improved through subsequent re-drying to meet industrial demand. Therefore, the results suggest that the conventional degree of yellowing in the flue-curing process needs to be reduced according to the settings of the flue-curing process from the re-drying perspective in the tobacco industry.

From the perspective of re-drying and cigarette processing, the authors propose an appropriate degree of yellowing for flue-curing as driven by the reform requirement from the supply side to improve the effectiveness of re-drying and tobacco processing. The conclusion is that it is necessary to treat both Hongda and K326 cultivars in tobacco-growing areas of Yunnan Province with 60 to $70 \%$ yellowing before $42{ }^{\circ} \mathrm{C}$ with a flue-curing process. This change would be most effectively brought about if the price structure was adjusted to render the tobacco obtained from mild yellowing more valuable to the farmer than that from regular yellowing in China.

\section{Acknowledgment}

This study was financially supported by several projects from the National Natural Science Foundation of China (No.41601330) and Yunnan Provincial Tobacco Monopoly Bureau, China (No. 2014YN13, 2016YN31 and 2017YN09). The authors are thankful to Dr. Mark S. Coyne for his valuable assistance and advice in the preparation of this paper.

\section{Authors' Contributions}

Conceptualization: Zou, C., Hu, X., Gu, H., Xiong, K. Data analysis: Zou, C., Hu, X., Huang, W., Zhao, G., Li, Y., Wu, Q. Design of methodology: Zou, C., Huang, W., Yang, X., Jin, Y., Yan, F. Software development: Zhao, G., Li, Y., Wu, Q. Writing and editing: Zou, C., $\mathrm{Hu}, \mathrm{X}$. , Xiong, $\mathrm{K}$.

\section{References}

Alejar, A.A.; de Visser, R.; Spencer, M.S. 1988. Ethylene production by attached leaves or intact shoots of tobacco cultivars differing in their speed of yellowing during curing. Plant Physiology 88: 329-332.

Bacon, C.W.; Wenger, R.; Bullock, J.F. 1952. Chemical changes in tobacco during flue-curing. Industrial \& Engineering Chemistry 44: 292-296.

Chen, H.L.; Dai, H.J.; Du, Y.G.; Cui, D.K.; Yu, J.J. 2011. Relationship of shatter resistance index and machinability of tobacco leaf. Tobacco Science \& Technology 10: 17-19 (in Chinese, with abstract in English).

Cui, G.M.; Huang, W.; Zhao, G.K. 2013. Effect of different fluecuring technologies on appearance grade quality and key chemical components of crude tobacco leaves. Horticulture \& Seed 9: 52-56 (in Chinese, with abstract in English).

Dai, L.; Huang, Y.C.; Gong, C.R.; Yu, J.H.; Yang, S.J. 2008. Effects of different temperature and humidity yellowing conditions on aroma constituents of tobacco leaves during bulk curing. Acta Agriculturae Boreali-Sinica 6: 148-152 (in Chinese, with abstract in English).

Gong, C.R.; Wang, Y.F.; Zhao, M.Q.; Zhao, H.J.; Lin, H.W. 1996. Effect of yellowing and leaf drying condition on the flavor characteristics of flue-cured tobacco leaves during curing. Acta Agriculturae Boreali-Sinica 3: 107-112 (in Chinese, with abstract in English).

Gong, C.R.; Wu, L.L.; Yuan, H.T.; Wang, G.L.; Yu, J.H.; Chen, C.Q. 2009. Effect of yellowing conditions on starch metabolism during curing process of tobacco leaf. Journal of Northwest A \& F University. Natural. Science Edition 37: 117-121 (in Chinese, with abstract in English).

Hawks, S.N.; Collins, W.K. 1993. Principles of Flue-Cured Tobacco Production. Collins-Hawks Books, Raleigh, NC, USA. 
He, F.; Wang, T.; Zhao, H.W.; Fan, S.J.; Yang, Y.M.; Gong, C.R. 2014. Changes of electrical properties of and chemical components in flue-cured tobacco during bulk curing. Tobacco Science \& Technology 2: 76-80 (in Chinese, with abstract in English).

Horne, W.P. 1980. Apparatus and Method for Automatically Controlling Curing Conditions in a Tobacco Curing Barn. United States Patent and Trademark Office, Washington, DC, USA. U.S. Patent 4,192,323 issued Mar 11, 1980.

Koiwai, A.; Kisaki, T. 1979. Changes in glycolipids and phospholipids of tobacco leaves during flue-curing. Agricultural and Biological Chemistry 43: 597-602.

Liu, T.J.; Zhang, R.C.; Yang, C.; Liu, Q.; Ma, J.G.; Xiong, J.; Chen, Y. 2015. Effect of different times of yellowing stage on usability of tobacco upper leaves. Southwest China Journal of Agricultural Sciences 1: 73-78 (in Chinese, with abstract in English).

Mutasa, E.S.; Seal, K.J.; Magan, N. 1990. The water content/water activity relationship of cured tobacco and water relations of associated spoilage fungi. International Biodeterioration 26: 381-396.

Peele, D.M. 2005. Tobacco Processing. United States Patent and Trademark Office, Washington, DC, USA. U.S. Patent 6,895,974 issued May 24, 2005.

Qian, Y.; Ren, S.H.; Xue, J.B.; Tang, J.X.; Liu, T.; Chen, H.F.; Yue, D.L.; Xu, H.Y. 2012. Influence of different yellowing degrees during the yellowing stages on the quality of fresh scent type flue-cured tobacco. Journal of Anhui Agricultural Sciences 27: 13608-13612 (in Chinese, with abstract in English).

Reed, T.D.; Johnson, C.S.; Semtner, P.J.; Wilkinson, C.A. 2012. Flue-Cured Tobacco Production Guide. Virginia Cooperative Extension, Blacksburg, VA, USA.

Roberts, E.H. 1941. Investigations into the chemistry of the fluecuring of tobacco. Biochemical Journal 35: 1289-1297.

Song, X.H.; Liu, G.S.; Fu, S.Y.; Zhang, C.H. 2010. Effects of prolonging the time of yellowing and leaf drying on neutral aroma constituents of tobacco leaves during curing. Acta Agriculturae Zhejiangensis 2: 249-252 (in Chinese, with abstract in English).
Stedman, R.L. 1968. Chemical composition of tobacco and tobacco smoke. Chemical Reviews 68: 153-207.

Tso, T.C. 1990. Production, Physiology, and Biochemistry of Tobacco Plant. Ideals, Beltsville, MD, USA.

Walton, L.R.; Henry, Z.A.; Henson Jr.; W.H. 1974. Moisture Diffusion in the Cured Burley Tobacco Leaf. University of Tennessee, Knoxville, TN, USA.

Wang, J.M.; Han, M.; Zhang, X.H.; Liu, Y.L.; Mu, L.; Li, K.; Ji, S.Y. 2011. Relationship between equilibrium moisture content and chemical indexes of flue-cured tobacco. Tobacco Science \& Technology 2: $43-46$ (in Chinese, with abstract in English).

Wang, N.R.; Xu, Z.H.; Li, Z.H.; Zhou, H.L.; Wang, D.S.; Zhu, X.L. 2007. Effect of Flue-curing and yellowing degree at later yellowing stage on the contents of free amino acids in the cured leaf. Journal of Anhui Agricultural Sciences 35: 1955-1956.

Wang, Y.B.; Wang, B.H.; Guo, C.F.; Wang, F.L.; Zhou, J. 1998. Study on the main chemical components related to smoking quality in flue-cured tobacco. Scientia Agricultura Sinica 31: 89-91.

Weston, T.J. 1968. Biochemical characteristics of tobacco leaves during flue-curing. Phytochemistry 7: 921-930.

Weybrew, J.A.; Wan Ismail, W.A.; Long, R.C. 1983. The cultural management of flue-cured tobacco quality. Tobacco International 185: 82-87.

White, F.H.; Pandeya, R.S.; Dirks, V.A. 1979. Correlation studies among and between agronomic, chemical, physical and smoke characteristics in flue-cured tobacco (Nicotiana tabacum L.). Canadian Journal of Plant Science 59: 111-120.

Xie, Y.H.; Zhu, L.Q.; Liu, Q.F.; You, D.G.; Li, W.W.; Zhang, Y.G. 2013. Advances Research in the effects of temperature and humidity on flue-cured tobacco quality during flue curing process. Journal of Agricultural Catastrophology 9: 60-63.

Zhan, J.; Li, W.; Huo, K.L.; Wang, D.B.; Gong, C.R. 2011. Effect of stabilized temperature duration on the aroma quality of upper flue-cured tobacco leaves during bulk curing process. Guangxi Agricultural Sciences 10: 1193-1198 (in Chinese, with abstract in English). 